\title{
Understanding the Thermo-Mechanical Behaviour of Solid Oxide Fuel Cell Anodes Using Synchrotron X-Ray Diffraction
}

T. M. M. Heenan ${ }^{1}$, J. B. Robinson ${ }^{1}$, X. Lu¹, B. Tjaden ${ }^{1}$, A. Cervellino², J. J. Bailey ${ }^{1}$, D.J.L. Brett ${ }^{1}$, P. R. Shearing ${ }^{1 *}$

1 Electrochemical Innovation Lab, Department of Chemical Engineering, UCL, London, UK, WC1E 7JE

2 Swiss Light Source, Paul Scherrer Institut, CH-5232 Villigen, Switzerland

* Paul R. Shearing, The Electrochemical Innovation Lab, Department of Chemical Engineering, University College London, WC1E 7JE, UK. Tel.: +44(0)20 7679 3783; Fax: +44 (0)20 7679 7092; E-mail: p.shearing@ucl.ac.uk

\begin{abstract}
The formation of cermet materials via the addition of electrolyte ceramic to metal-based electrodes has become widely adopted in solid oxide fuel cell fabrication due to its benefits in maximizing triple-phase boundary densities, while mitigating bulk thermal expansion mismatch between electrode and electrolyte layers. This work improves thermo-mechanical understanding via examination of nickel-based anode materials using synchrotron X-ray diffraction; two cermet materials are studied: $N i-Y S Z$ and $N i-G D C$, with comparison to a ceramic-free $N i$ sample. Findings conclude that although the ceramic addition has minor effects on the cubic $N i$ structure within isothermal environments, stress induced by the different thermal properties within the cermet materials results in a shifted $N i$ thermal expansion peak on passing the Curie point. Moreover, extended cycling of the $\mathrm{Ni}$-YSZ sample suggests that low-temperature operation $\left(\mathrm{ca} .600{ }^{\circ} \mathrm{C}\right)$ may require several thermal cycles, or extended dwell times, to alleviate residual $\mathrm{Ni}$ stresses, this has potential implications for SOFC design and operation strategies.
\end{abstract}

\section{Highlights}

- The effects of ceramic addition to the expansion of the cubic structure of $\mathrm{Ni}$ in isothermal environments are minor over a single thermal cycle.

- Accelerated stress tests revealed that lower temperature operation, i.e. $600{ }^{\circ} \mathrm{C}$ rather than higher $1000{ }^{\circ} \mathrm{C}$, results in deformation of the lattice parameters at both, low and high temperatures, likely due to a combination of two mechanisms: shock-induced tensile stress and delayed relaxation hysteresis.

- High and low temperature deformation has been found to be divergent resulting in a greater relative deformation in the cold lattice parameters.

- The thermal expansion non-linearity on passing the Ni Curie temperature is not suppressed; however, it is shifted to a higher temperature, a temperature that is dependent upon the ceramic employed.

Keywords

SOFC; Ni-YSZ; XRD; Curie Temperature; Degradation.

\section{Introduction}

The high temperature of operation of SOFCs offer advantages due to favorable kinetics [1] using lower cost nickel based catalysts and flexible fueling options with the ability to recover excess heat [2, 3]. However, the desire to increase thermal ramp-rates to achieve rapid start-up and shut-down times drives concerns about thermally driven stack degradation. Whilst thermo-mechanical simulations of SOFCs during cycling is advancing [4 - 6] novel characterization and experimental methods [7 - 11] are still required to improve the accuracy of modeling tools and provide validation [12].

The performance of SOFCs can be characterized by the direct analysis of the kinetic, ohmic or diffusive properties using techniques such as electrochemical impedance spectroscopy (EIS) [13], or by indirect analysis using materials characterisation techniques. The proliferation of tomography tools [14 - 16] has enabled the quantification of a range of geometrical parameters, including the triple phase boundary density $(T P B)$. In order to maximize $T P B$ density and minimize the difference in thermal expansion between the neighbouring electrode and electrolyte layers, the electrolyte ceramic is added to the metallic electrode forming a cermet. Nickel-based $(\mathrm{Ni})$ anodes are commonly employed in combination with either yttria-stabilised zirconia (YSZ) or gadolinium-doped ceria $(G D C)$, forming $N i$-YSZ or $N i$-GDC cermets, respectively [17, 18]. Whilst the crystallography of pure $N i$ is well-understood [19 - 23] the influence of such ceramic addition has been the subject of increased research in recent years [24 - 29].

Non-uniform thermal expansion within SOFCs is a known cause of unfavorable strain distribution [24, 25] therefore, the location and cause of any non-linear expansion is of interest in mitigating mechanical degradation in the form of delamination and cracking, and the subsequent loss in electrochemical performance. The Curie point is the temperature that is thermodynamically sufficient to disrupt dipole alignments causing a magnetic transition from ferromagnetism to paramagnetism. This transition results in a well-documented nonlinearity in the $N i$ thermal expansion coefficient (TEC) [19-23]; although, the temperature at which metals are able to exhibit ferromagnetism is thought to be sensitive to the level of strain to which the material is subjected to [30], and correlation has also been observed between the sintering and Néel temperature [31]. 
Studies using macroscopic techniques such as dilatometry have suggested that bulk non-linearity is suppressed to insignificant values by the addition of the supporting ceramic backbone [32]. However, the microscopic interactions between the metal and ceramic phases (at the TPB) are thought to be of great thermomechanical importance [6] and it has been suggested by techniques such as thermomechanometry that the nonlinear expansion of the metallic phase may remain regardless of the presence of the ceramic [33].

Long-duration operation can cause undesirable agglomeration reducing $T P B$ density $[1,34] . N i$ is also known to undergo thermally driven deformation $(T D D)$ in the form of mechanical creep observed through lattice hysteresis during thermal cycling, thought to be attributable to temperature-triggered stress relaxation due to lattice distortions and imperfections held in residual stress within the metal [24]. Improved understanding of these mechanisms is required.

In this work, we investigate three materials: $N i, N i$-YSZ and $N i$-GDC using in-situ synchrotron X-ray diffraction to explore the influence of ceramic addition on the mechanical properties of the metal during thermal cycling. For the first time known to the authors, the location of the $\mathrm{Ni}$ Curie transition temperature and lattice variation during operational thermal cycling are examined, thereby improving the understanding of metalceramic interaction within cermet materials. This understanding of the thermo-mechanical interaction between ceramic and metal within cermet materials will ultimately lead to improved cell performance and lifetimes; knowledge that is also transferable to comparable materials where metal and ceramic interfaces prove critical to performance.

\section{Materials and method}

Three commonly employed SOFC anode materials were examined via synchrotron powder diffraction: $N i$ (Novamet Specialty Products Corp, Lebanon), Ni-YSZ (Fuel Cell Materials, OH, USA) and Ni-GDC (Fuel Cell Materials, OH, USA). The zirconia powder was supplied with $8 \mathrm{~mol} \%$ yttria content, $\left(\mathrm{Y}_{2} \mathrm{O}_{3}\right)_{0.08}\left(\mathrm{ZrO}_{2}\right)_{0.92}$, and the ceria powder was supplied with $10 \mathrm{~mol} \%$ gadolinia doping, $\mathrm{Gd}_{0.10} \mathrm{Ce}_{0.90} \mathrm{O}_{2}$. Both cermet materials, $\mathrm{Ni}$ - $Y S Z$ and $\mathrm{Ni}-\mathrm{GDC}$, were supplied with a 60:40 composition of metal to ceramic by weight, and the ceramic-free powder is supplied at $99.6 \%$ purity with the residual volume consisting of $3000 \mathrm{ppm}$ oxygen, $800 \mathrm{ppm}$ iron, $30 \mathrm{ppm}$ carbon and $30 \mathrm{ppm}$ sulphur.

Initially, powders were formed into cylindrical pellets by iso-static pressing and subsequently sintered at $1200{ }^{\circ} \mathrm{C}$ for 2.5 hours in air. The pellets were then reduced in forming gas $\left(4 \% \mathrm{H}_{2}\right.$ in $\left.96 \% \mathrm{~N}_{2}\right)$ for 2 hours at $800{ }^{\circ} \mathrm{C}$; reduction of $\mathrm{NiO}$ to $\mathrm{Ni}$ was confirmed with Raman spectroscopy, see Fig. 1a. The reduced pellets were then ground into powders using diamond files and inserted into open-ended quartz capillary tubes, $10 \mathrm{~cm}$ in length with internal diameter of $580 \mu \mathrm{m}$, see Fig. $1 \mathrm{~b}$.

Crystallographic investigations were conducted at the X04SA-MS beamline [35] (Swiss Light Source, Paul Scherrer Institute, Switzerland). The samples within the capillary tubes were inserted into a goniometer head (HUBER Diffraktionstechnik GmbH \& Co. KG, Germany) via a brass button seal, and positioned perpendicular to the X-ray beam. A hot-air blower was placed below the capillary tube, coincident with the Xray beam, in order to collect diffraction patterns at elevated temperatures. To increase the accuracy of temperature recordings a thin, high precision thermocouple ( $\mathrm{ca} .250 \mu \mathrm{m}$ in diameter) was inserted into the capillary, until coincident with the horizontal X-ray beam and vertical hot-air blower, see Fig. 1c. To prevent oxidation of the samples, premixed gas ( $5 \% \mathrm{H}_{2}$ in $95 \% \mathrm{~N}_{2}$ ) was passed over the sample at a continuous rate of $25 \mathrm{~mL} \mathrm{~min}^{-1}$. All diffraction patterns were collected at two theta angles from $-60^{\circ}$ to $+60^{\circ}$ at $26 \mathrm{keV}(0.4788 \AA$ ) using a MYTHEN II (microstrip system for time-resolved experiments) detector covering $120^{\circ}$ with over 60,000 channels on a double layer for a $0.0036^{\circ}$ intrinsic resolution (microstrip system for time-resolved experiments) at an exposure of 60 seconds per detector. 

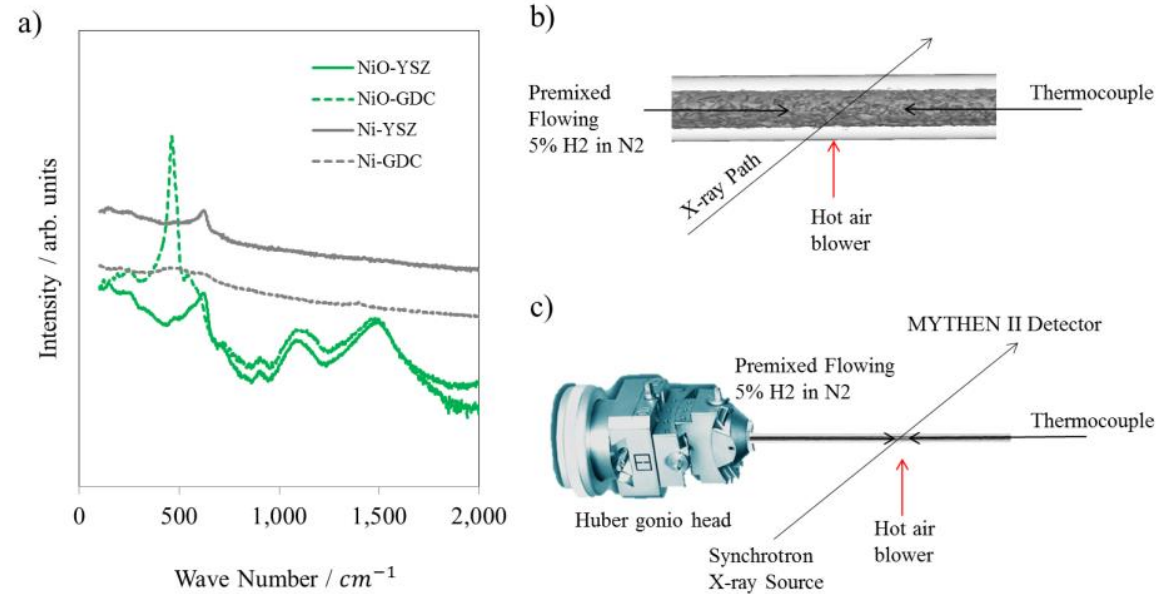

Fig. 1 Experimental set-up for diffraction collection at the X04SA-MS Beamline: (a) pre- and post-reduction Raman spectra, (b) four coincident paths of the hot-air blower, forming gas, thermocouple and X-ray beam, and (c) sample mounting via a quartz capillary packed with sample powder [36].

For reference, diffraction patterns of the empty capillary were collected for all temperatures. A background removal was also applied to all patterns before extracting lattice parameters of interest [37]. $\mathrm{Ni}$ and $\mathrm{NiO}$ peak intensities are compared in Fig. 2 a to confirm no re-oxidation of the $\mathrm{Ni}$ during thermal cycling, one thermal ramp is presented here but this was conducted for all data sets. A corrected Ni-YSZ pattern is displayed in Fig. $2 \mathrm{~b}$ with $\mathrm{Ni}$ peak locations compared to a reference for several crystallographic indices displayed in Fig. 2c [24]. Very minor deviations were observed achieving a coefficient of determination close to unity $\left(R^{2}=0.998\right)$.
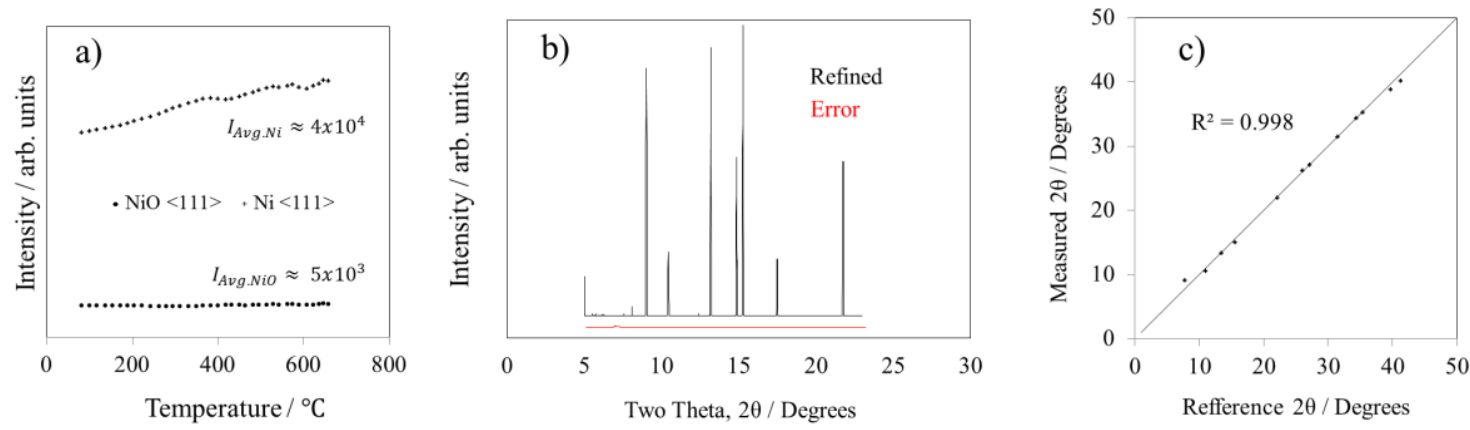

Fig. 2 Confirmation of diffraction data quality: (a) $\mathrm{Ni}$ and $\mathrm{NiO}$ peak intensities plotted with respect to temperature, (b) corrected pattern from a $N i$-YSZ diffraction, and (c) nickel peak locations with comparison to a reference for several crystallographic orientations with coefficient of determination $\left(R^{2}=0.998\right)$ [24].

Firstly, diffraction patterns were collected through both heating and cooling during one thermal cycle for each of the three materials: $\mathrm{Ni}, \mathrm{Ni}-\mathrm{YSZ}$ and $\mathrm{Ni}-\mathrm{GDC}$. Patterns were collected continuously resulting in one pattern every two minutes at a ramp rate of $c a .10^{\circ} \mathrm{C} \cdot \mathrm{min}^{-1}$ from $c a .100{ }^{\circ} \mathrm{C}$ to $650{ }^{\circ} \mathrm{C}$ and back to $100{ }^{\circ} \mathrm{C}$; equating to $c a$. 2 hours of data acquisition per sample. These data sets were collected to inspect hysteresis and non-linearity in the $\mathrm{Ni}$ phase. Further diffraction patterns were collected from fresh samples over an additional thermal cycle for the Curie transition $\mathrm{ca} .250^{\circ} \mathrm{C}$ to $550^{\circ} \mathrm{C}$ for the three materials using a reduced ramp-rate of $5^{\circ} \mathrm{C} \cdot \mathrm{min}^{-1}$.

Extended thermal cycling was then conducted on a Ni-YSZ sample. One thermal cycle was conducted at $c a .10^{\circ} \mathrm{C} \cdot \mathrm{min}^{-1}$, followed by four additional thermal cycles at an accelerated stress-test rate of $c a$. $60{ }^{\circ} \mathrm{C}$. $\mathrm{min}^{-1}$. For these high ramp rates, data were collected only at $100{ }^{\circ} \mathrm{C}$ and $600{ }^{\circ} \mathrm{C}$, i.e. no data was collected during thermal ramping. Temperature was held constant during data collection to allow enough dwell time for thermal equilibrium to be reached, $c a$. 25 mins.

The lattice parameters, thermal strains and thermal stresses for three orientations of $\mathrm{Ni}:<111>$, $<$ $200>$ and $<220>$, were obtained sequentially from the thermal cycle of each material: $\mathrm{Ni}, \mathrm{Ni}-\mathrm{YSZ}$ and $\mathrm{Ni}$ $G D C$. It is important to consider multiple orientations because, unless oxidized, $N i$ should retain a face-centered cubic $(F C C)$ structure throughout each data acquisition, i.e. independent of ceramic addition, resulting in an isotropic expansion and contraction with temperature change although, the authors have previously proven this 
is not necessarily the case for non-isothermal environments [7]. Therefore by examining these three families of Miller indices, as visualized in Fig. 2c-e, any non-isotropic effects of ceramic addition can be examined.

\section{Calculations}

Similar to methods previously reported by the authors [24], the average interplanar distances $(d)$ are obtained from the diffraction angle $(\theta)$ and the wavelength of the X-ray beam $(\lambda)$, using Bragg's law with the positive integer $(n)$ equal to unity. Having a face-centred cubic crystal structure, the lattice parameters $(L)$ for nickel are obtained from the diffraction angle using the Miller indices $(h, k$ and $l)$ and the relation for a cubic system. Thermal strain $\left(\varepsilon_{\text {thermal }}\right)$ is calculated from the lattice variation with respect to a chosen state; for this work, the point of zero strain is taken at the maximum temperature, thus the maximum lattice parameter $\left(L_{0}\right)$, Equation 1. The thermal stress ( $\left.\sigma_{\text {thermal }}\right)$ is obtained from the product of the thermal strain and the Young's $(E)$ modulus of the material, Equation 2. A local thermal expansion coefficient (TEC) can be calculated through the thermal cycle of each material using the change in local lattice parameters $(d L)$ at each temperature increment $(d T)$, Equation 3. Thermal driven deformation can be quantified by the change in lattice parameter with respect to an initial condition $\left(L_{i}\right)$, Equation 4 .

$$
\begin{aligned}
& \varepsilon_{\text {thermal }}=\frac{L-L_{0}}{L_{0}} \\
& \sigma_{\text {thermal }}=E \times \varepsilon_{\text {thermal }} \\
& T E C=\frac{1}{L} \frac{d L}{d T} \\
& T D D=\left[\frac{L}{L_{i}}-1\right] \times 100
\end{aligned}
$$

\section{Results and discussion}

\subsection{A single thermal cycle of $\mathrm{Ni}, \mathrm{Ni}-\mathrm{YSZ}$ and $\mathrm{Ni}-\mathrm{GDC}$}

The lattice parameters, thermal strain and thermal stress for three orientations of Ni: $<111\rangle,<200\rangle$ and $<$ $220>$, are obtained from the thermal cycle of each material: $N i, N i-Y S Z$ and $N i-G D C$. The lattice parameters displayed in Fig. 3 - 5 show close similarity with those presented previously [19-23], and the thermal stress, calculated using the Young's modulus values reported by Pihlatie et al. [38], also show good agreement with related work [24].

First, we consider the ceramic-free $N i$ sample, and examine the crystallographic information obtained from $N i$ without the influence of a constraining ceramic skeleton, see Fig. 3. The lattice expansion and contraction patterns display very similar values for heating and cooling, as do the three crystallographic orientations; suggesting that an FCC structure is maintained throughout the temperature range examined. Nonlinearity and subtle hysteresis is seen near the Curie temperature of $N i, c . a .354{ }^{\circ} \mathrm{C}$, but with the exception of the Curie temperature distortion, the resulting stress and strain variation displays a linear trend with the lattice parameters returning to a very similar value after the thermal cycle to that which was seen before thermal ramping, $3.525 \AA$.

Secondly, we examine the $N i$ lattice expansion within a composite material of $N i$ and YSZ, see Fig. 4. Similarity in the lattice patterns for the three orientations again suggests a $F C C$ structure is maintained throughout the temperature range examined. Non-linearity and hysteresis is again seen near the Curie temperature of $\mathrm{Ni}$ although within the cermet material the hysteresis appears to extend to temperatures above the Curie point. This is possibly a result of the interaction between the metal and ceramic during this transition; ceramic materials have previously been reported to influence the $N i$ expansion causing deviation from linearity [13]. Away from the Curie temperature the resulting stress and strain variation again displays relatively linear expansion and contraction with the lattice parameters returning to a similar value after the thermal cycle to that which was seen in the ceramic-free sample.

Thirdly, crystallographic information of $\mathrm{Ni}$ is examined within the $\mathrm{Ni}-G D C$ cermet, see Fig. 5. Away from the Curie point, relatively linear strain and stress are observed, but notable deviation is observed between the three lattice orientations, particularly about the Curie point and at the highest temperatures examined. Furthermore, large hysteresis looping is seen, primarily within the $\langle 111\rangle$ orientation, although the lattice parameters observed after the single thermal cycle are similar to that seen in both the YSZ cermet and ceramicfree samples; indicating the hysteresis experience in this region is negligible for a single cycle.

The $N i$ lattice parameters displayed here present near-elastic cycling in all three samples; the roomtemperature lattice parameters before and after thermal cycling deviate in insignificant amounts over a single cycle. However, it is conceivable that what is considered negligible deviation over a single thermal cycle could 
accumulate to significant amounts over prolonged operational cycling. Moreover, undesirable expansion in the form of non-linearities may result in an increased population of dislocations within the crystalline structure. It is therefore important to understand the effects of ceramic addition to the metal lattice dynamics about any nonlinear expansion.
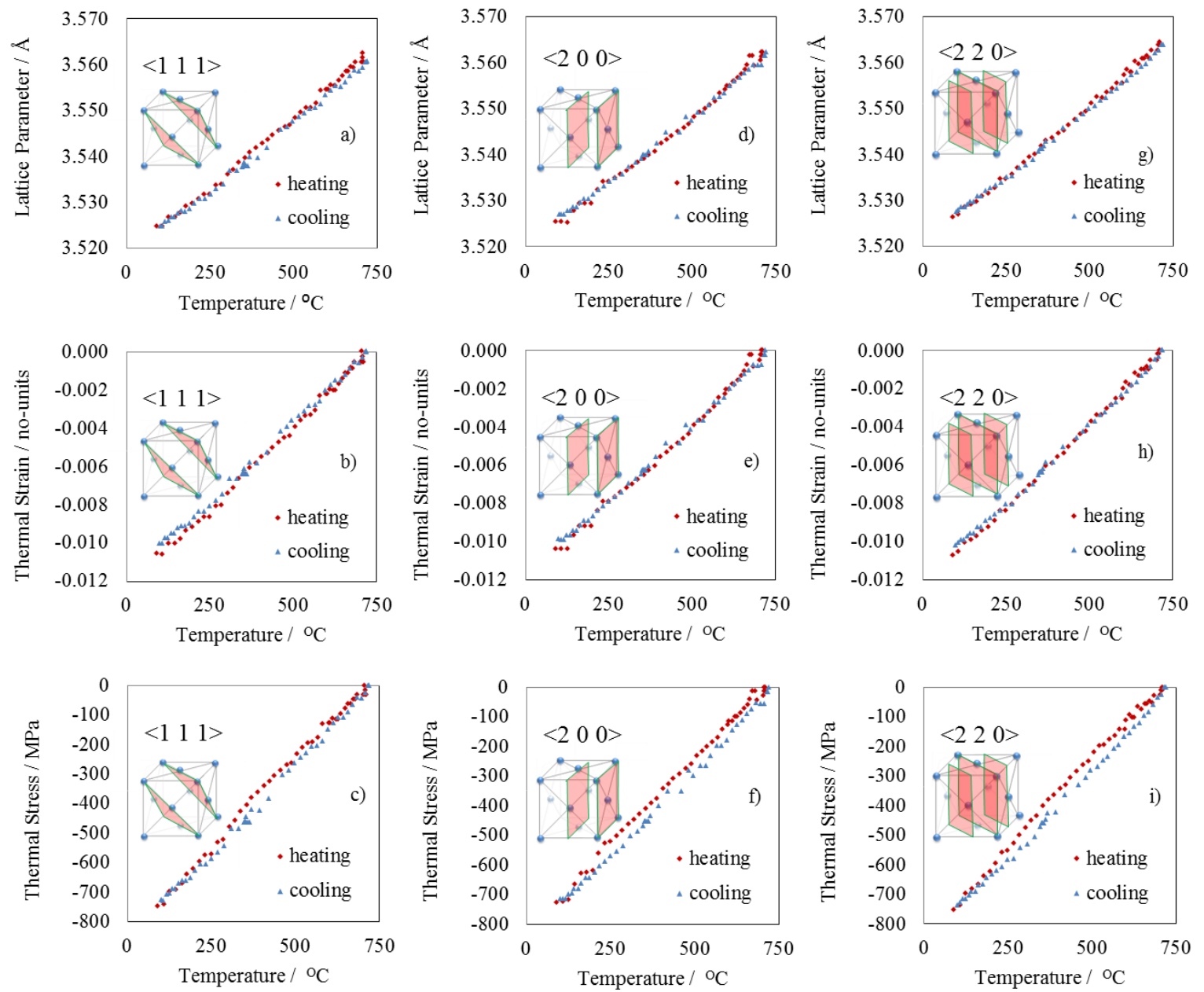

Fig. 3 Lattice parameters with accompanying crystallographic strain and stress mapping for $N i\langle 111\rangle,\langle 200\rangle$ and $<$ $220>$ obtained from powdered diffraction of $N i$ using synchrotron X-ray powder diffraction at $26 \mathrm{keV}:(\mathrm{a}-\mathrm{c})$ lattice, (d f) strain and $(h-j)$ stress variation with temperature. 

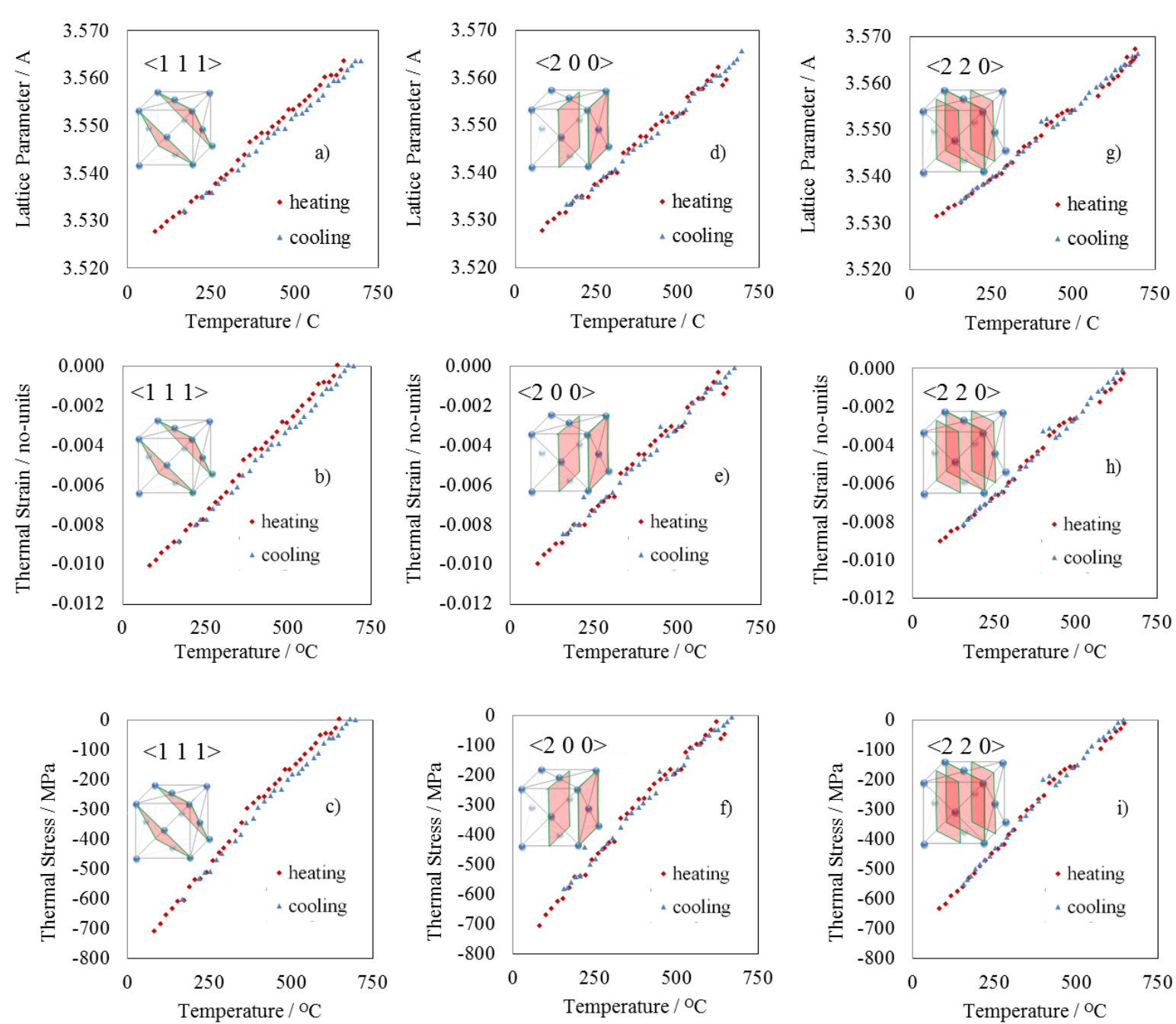

Fig. 4 Lattice parameters with accompanying crystallographic strain and stress mapping for $N i<111>,<200>$ and $<$ $220>$ obtained from powdered diffraction of $N i-Y S Z$ using synchrotron X-ray powder diffraction at $26 \mathrm{keV}:(\mathrm{a}-\mathrm{c})$ lattice, $(d-f)$ strain and $(h-j)$ stress variation with temperature. 

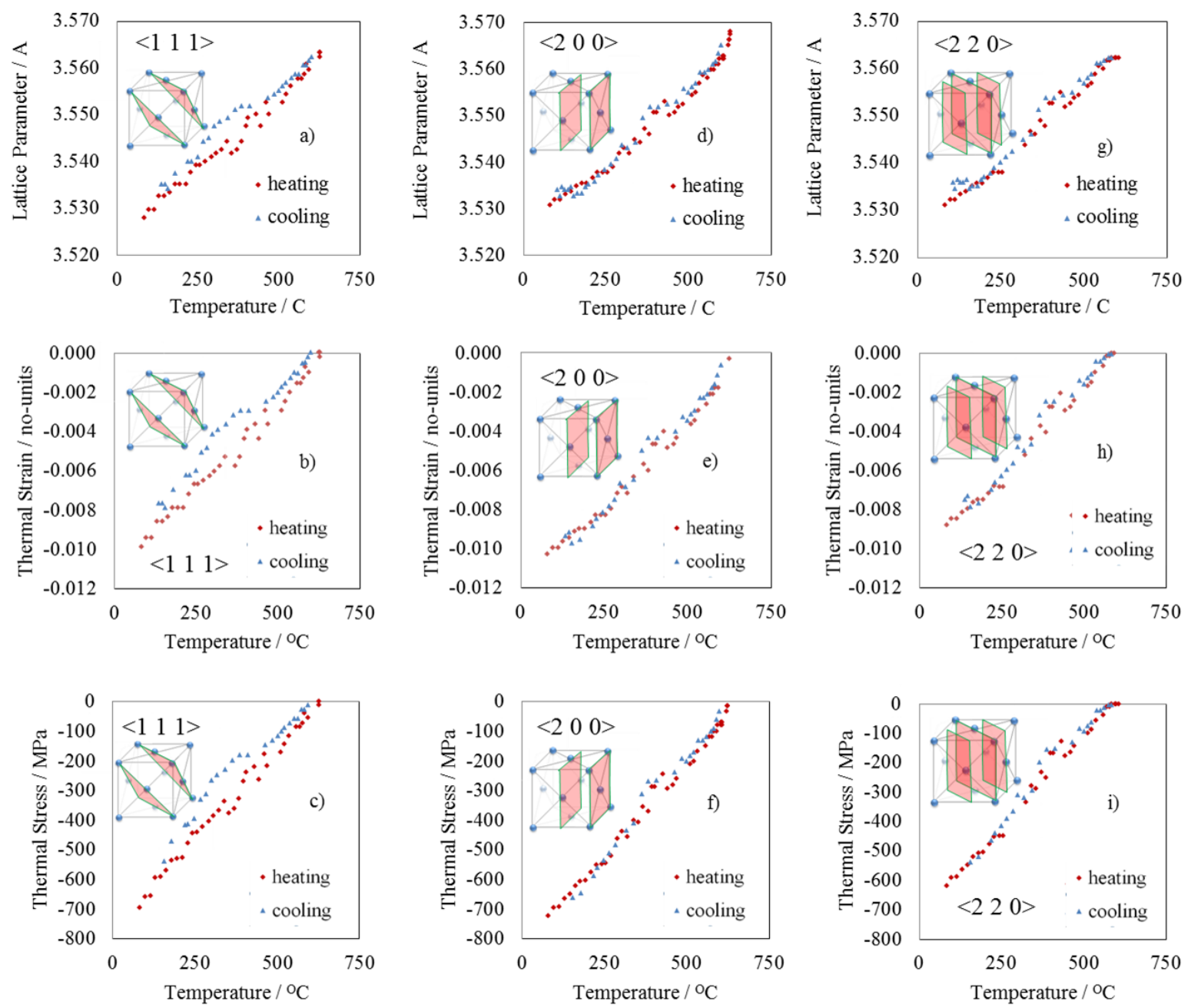

Fig. 5 Lattice parameters with accompanying crystallographic strain and stress mapping for $N i<111>,<200>$ and $<$ $220>$ obtained from powdered diffraction of $\mathrm{Ni}-\mathrm{GDC}$ using synchrotron X-ray powder diffraction at $26 \mathrm{keV}:(\mathrm{a}-\mathrm{c})$ lattice, $(d-f)$ strain and $(h-j)$ stress variation with temperature.

\subsection{Non-linear $\mathrm{Ni}$ thermal expansion coefficient}

The thermal expansion coefficient (TEC) variation about the Curie point, $354^{\circ} \mathrm{C}$ [19], for each material is displayed in Fig. 6. Fig 6a shows the $N i$ orientations within ceramic-free $N i$, in Fig 6b, the TEC data is compared with several reference sources [19-23] and in Fig. 6c, the comparison of the $N i<111>$ orientation within $\mathrm{Ni}, \mathrm{Ni}-\mathrm{YSZ}$ and $\mathrm{Ni}-\mathrm{GDC}$ is presented. The magnitude of the non-linear $\mathrm{Ni}$ peak $\left(T E C_{\text {peak }}\right)$ and the temperature where the peak is located $\left(T_{\text {peak }}\right)$ are displayed in Table 1 for all three orientations. Comparative data from diffraction [22, 23] and dilatometry [32] experiments from the literature are also presented. For the ceramic-free sample it can be seen that the values for both $T_{p e a k}$ and $T E C_{\text {peak }}$ present close similarity to values that have been reported in literature.

Table 1 Temperature and magnitude of the non-linear thermal expansion coefficient peak on passing the $\mathrm{Ni}$ Curie point for three $\mathrm{Ni}$ orientations within ceramic-free $\mathrm{Ni}$ respect to three references.

\begin{tabular}{cccc}
\hline Sample & $T_{\text {peak }} /{ }^{\circ} \mathrm{C}$ & $T E C_{\text {peak }} / x 10^{-6}{ }^{\circ} \mathrm{C}^{-1}$ & Reference \\
\hline$N i<111>$ & 354 & 18.1 & Measured \\
$N i<200>$ & 351 & 17.8 & Measured \\
$N i<220>$ & 351 & 18.0 & Measured \\
$N i<111>$ & 354 & 17.7 & {$[22]$} \\
$N i<111>$ & 355 & 18.8 & {$[21]$} \\
$N i$ Dilatometry & 350 & 17.5 & {$[31]$} \\
\hline
\end{tabular}

Previous dilatometry studies conducted on $\mathrm{Ni}$ and $\mathrm{Ni}$-YSZ have reported bulk suppression of TEC non-linearity through the addition of a constraining ceramic backbone. Mori et al. presented a $5 \times 10^{-6}{ }^{\circ} \mathrm{C}^{-1}$ reduction in 
the bulk $N i$-YSZ material TEC near the Curie temperature, resulting in greatly increased linearity of thermal expansion for $\mathrm{Ni}$-YSZ compared to $\mathrm{Ni}$ alone. Unlike X-ray diffraction, techniques such as dilatometry are limited to providing only macroscopic bulk effects resulting in limited information regarding the constituent materials at the microscopic/crystallographic level. Here, the TEC of $\mathrm{Ni}$ was examined for cermet materials $\mathrm{Ni}$-YSZ and $\mathrm{Ni}$ $G D C$ as well as metallic $N i$, from $250{ }^{\circ} \mathrm{C}$ to $550{ }^{\circ} \mathrm{C}$ to understand the effects of ceramic addition on the $T_{\text {peak }}$ location and $T E C_{\text {peak }}$ magnitude.
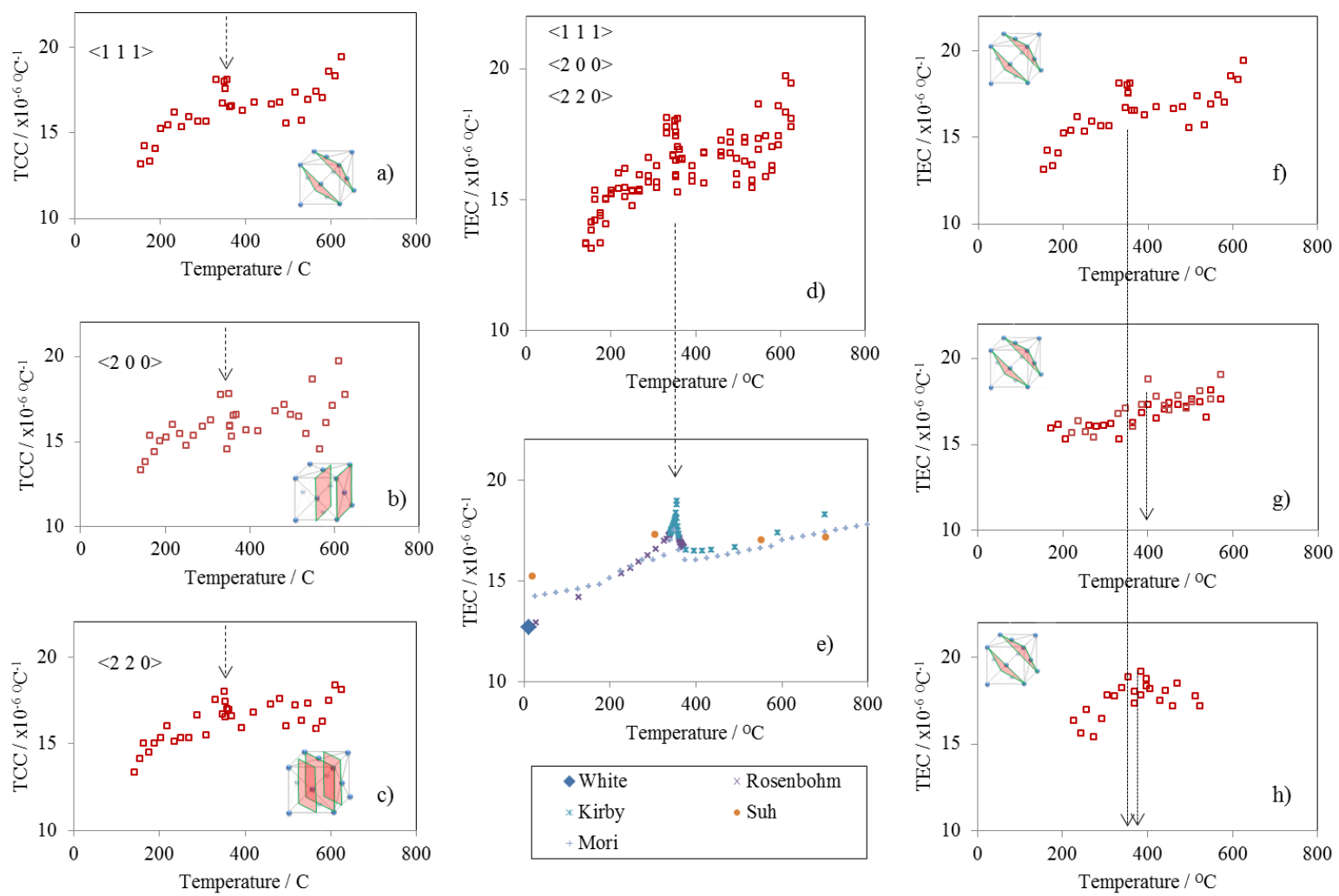

Fig. 6 Non-linear thermal expansion coefficient for $\mathrm{Ni}$ on passing the Curie point: three orientations of $\mathrm{Ni}$ (a) $<111\rangle$, (b) $<200>$ and (c) $<220>$, (d) collectively compared to (e) several references [19, $21-23,32]$ and a comparison of $N i$ $<111>$ within (f) Ni, (g) Ni-YSZ and (h) Ni-GDC.

Table 2 presents the $T_{\text {peak }}$ location and $T E C_{\text {peak }}$ magnitude for the $N i<111>$ orientation for the ceramic-free $\mathrm{N} i$, and the two ceramic containing cermet materials. We observe that whilst macroscopically the ceramic addition may constrain the $N i$ expansion enough to overcome any non-linear TEC behavior [32], non-linearity in the $N i$ crystallography remains and ceramic addition does not suppress non-linear crystallographic $N i$ expansion.

Table 2 Temperature and magnitude of the non-linear thermal expansion coefficient peak on passing the $\mathrm{Ni}$ Curie point for one $\mathrm{Ni}$ orientations $<111>$ within three materials: $\mathrm{Ni}, \mathrm{Ni}-\mathrm{YSZ}$ and $\mathrm{Ni}-\mathrm{GDC}$

\begin{tabular}{ccc}
\hline Material & $T_{\text {peak }} /{ }^{\circ} \mathrm{C}$ & $T E C_{\text {peak }} / \times 10^{-6}{ }^{\circ} \mathrm{C}^{-1}$ \\
\hline $\mathrm{Ni}$ & 354 & 18.1 \\
$\mathrm{Ni}$-GDC & 385 & 19.2 \\
$\mathrm{Ni}$-YSZ & 402 & 18.8 \\
\hline
\end{tabular}

The $N i$ lattice parameter increases with increasing temperature and the temperature at which the non-linear $N i$ thermal expansion peak occurs is shifted to a higher temperature for cermet materials (Fig. $6 \mathrm{~g}$ and $\mathrm{h}$ ). Thus the lattice parameter immediately preceding the non-linear expansion, i.e. the onset lattice parameter, is higher in cermet materials than that which is observed in pure metal (Fig. 6f). Therefore it should be noted that the magnitude of the thermal expansion peak within cermet materials can be expected to be higher than that of pure $\mathrm{Ni}$, an increase possibly attributed to the higher onset lattice parameter.

The reason why the expansion peak is not observed with techniques such as dilatometry [32] is likely due to the macroscopic stiffness that suppresses large expansion. However because these materials are porous, stress relaxation is thought to occur at microscopic length scales within the Ni phase via expansion into neighboring pores [6, $39-41]$ and consequently the non-linear expansion can still be observed for crystallographic studies. 
The temperature at which non-linearity is observed, $T_{\text {peak }}$, shifts within the cermet materials; the $N i$ Curie transition is reported at $354^{\circ} \mathrm{C}$ by several sources $[21,22,32]$ which agrees closely with the ceramic-free $\mathrm{Ni}$ data, but a shift of $\mathrm{ca} .30^{\circ} \mathrm{C}$ and $50^{\circ} \mathrm{C}$ is observed for $\mathrm{Ni}$-GDC and $\mathrm{Ni}$-YSZ, respectively. We hypothesize two possible mechanisms contributing to the peak shift: mechanical rigidity of the ceramic backbone and the altered population of crystallographic dislocations. Firstly, the mechanical stiffness may increase the energy required to cause the $\mathrm{Ni}$ restructuring due to the constraining backbone which mechanically restricts expansion; the mechanical constraint caused by the ceramic backbone is thought to be of great importance particularly at the metal-ceramic interface [6,40,41]; the magnitude of this constraint being a function of the Young's modulus of the ceramic. Secondly, the ceramic addition may alter the dislocation density within the metal favoring ferromagnetism; it has been suggested that lattice distortions associated with crystallographic dislocations promote the emergence of ferromagnetism [31].

A reduced ramp-rate during the Curie transition may allow for the dissipation of undesirable thermal shock experienced due to the non-linear expansion, by prolonging the opportunity for the $\mathrm{Ni}$ phase to relax into the porous phase and alleviating interfacial stress peaks. This may possibly be beneficial in the design of thermal control systems for SOFCs operating under conditions where high ramp rates are anticipated.

\subsection{Accelerated stress-test cycling of $\mathrm{Ni}$-YSZ}

Finally, the lattice parameters with accompanying thermal strain and stress are presented for an accelerated stress test (AST) using the Ni-YSZ material, as displayed in Fig. $7 \mathrm{a}-\mathrm{c}$. Data was acquired for one full thermal cycle at a ramp rate of $c a .10^{\circ} \mathrm{C} \cdot \mathrm{min}^{-1}$ followed by data acquisition only at low $\left(100{ }^{\circ} \mathrm{C}\right)$ and high $\left(600{ }^{\circ} \mathrm{C}\right)$ temperatures with sequential cycling at an accelerated rate of $c a .60^{\circ} \mathrm{C} . \mathrm{min}^{-1}$. ASTs such as this allows for the analysis of residual stress relaxation and thermally induced shock both observed in the form of $T D D$ over the course of many cycles providing an insight into real-life, long-term thermal operation that would otherwise be very time intensive.
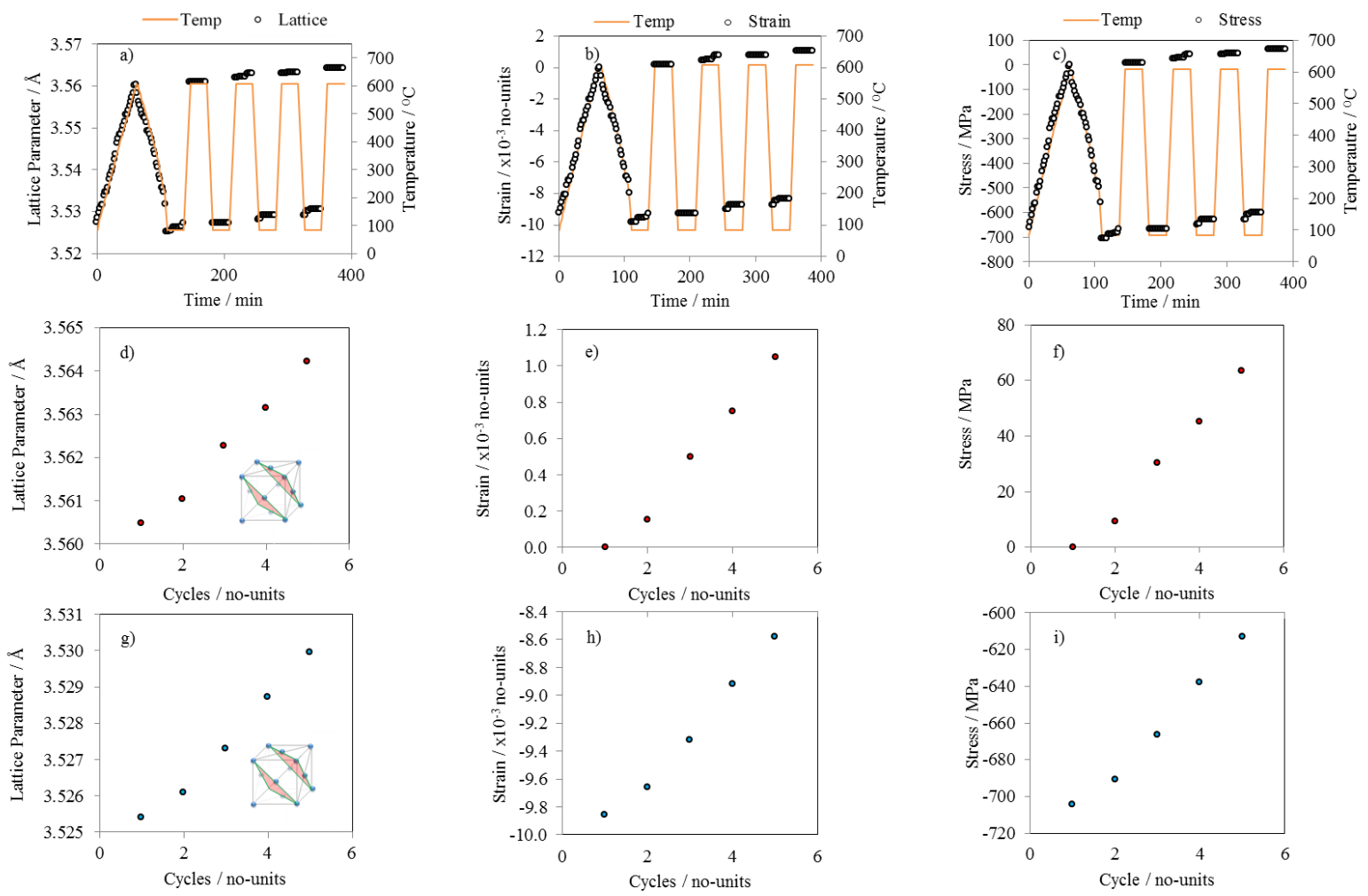

Fig. 7 Thermal cycling of $\mathrm{Ni}-\mathrm{YSZ}$ powder examining the variation of the $<111>$ lattice parameter within $\mathrm{Ni}$ for five thermal cycles from low temperature $\left(100^{\circ} \mathrm{C}\right)$ to operating temperature $\left(650^{\circ} \mathrm{C}\right)$ in a forming gas environment: a) lattice, b) strain and c) stress variation with thermal cycling, high-temperature d) lattice, e) strain and f) stress, and low-temperature g) lattice, h) strain and i) stress, variation with thermal cycles.

For each thermal cycle, the sample was held at the low temperature while several patterns were collected (see Fig. 7a at 100-120 mins), the lattice parameter for these acquisitions was then averaged (see Fig. $7 \mathrm{~g}$, Cycle 1). This process was repeated for the high-temperature acquisitions, then for each thermal cycle in turn, resulting in 
a variation in the five high (Fig. 7d) and five low (Fig. 7g) lattice parameters with respect to the number of thermal cycles. These values were then used to calculate the thermal strain variation with respect to the initial high-temperature lattice parameter (Fig. 7e and h), and the thermal stress calculated from the results (Fig. $7 \mathrm{f}$ and i).

Table 3 Low temperature crystallographic data for the $\mathrm{Ni}<111>$ orientation from a $\mathrm{Ni}$-YSZ sample exposed to five thermal cycles with strain and stress calculated with respect to the initial thermal cycle.

\begin{tabular}{cccc}
\hline Cycle & Lattice $/ \AA$ & Strain $/ \times 10^{-3}$ no-units & Stress / MPa \\
\hline 1 & 3.525 & -9.9 & -704 \\
2 & 3.526 & -9.7 & -690 \\
3 & 3.527 & -9.3 & -666 \\
4 & 3.529 & -8.9 & -638 \\
5 & 3.530 & -8.6 & -613 \\
\hline
\end{tabular}

Table 4 High temperature crystallographic data for the $N i<111>$ orientation from a $N i-Y S Z$ sample exposed to five thermal cycles with strain and stress calculated with respect to the initial thermal cycle.

\begin{tabular}{cccc}
\hline Cycle & Lattice $/ \AA$ & Strain $/ \times 10^{-3}$ no-units & Stress / MPa \\
\hline 1 & 3.560 & 0.0 & 0 \\
2 & 3.561 & 0.2 & 9 \\
3 & 3.562 & 0.5 & 30 \\
4 & 3.563 & 0.7 & 45 \\
5 & 3.564 & 1.0 & 63 \\
\hline
\end{tabular}

$T D D$ is seen in both the high and low-temperature lattice parameters; the lattice parameters are seen to increase with thermal cycling, resulting in a positive shift for strain and stress with respect to the initial thermal cycle. Marginally more creep is seen in the low temperature (Table 3) parameters than that observed at high temperatures (Table 4), possibly due to increased mobility at high temperatures resulting in greater relief of residual stresses on heating compared to cooling. This is examined more closely in Table 5 by the quantification of the thermally driven deformation into $T D D$ values from both the low $(3.525 \AA)$ and high $(3.560 \AA)$ temperature lattice parameters. Although both high and low temperature $T D D$ correlate positively with increasing number of thermal cycles, the $T D D_{L T}$ and $T D D_{H T}$ values display a locally divergent path; the hightemperature deformation follows a near-linear increase with each thermal cycle, whereas the low-temperature deformation shows consistently greater deformation with each thermal cycle which accelerates non-linearly, particularly after the third thermal cycle. The locally divergent deformation is quantified by the difference in the high- and low-temperature deformation $(\triangle T D D)$, also displayed in Table 5.

Table 5 Thermally driven deformation of the $N i<111>$ lattice parameter within $N i$-YSZ quantified with respect to increasing thermal cycles from the low $(3.525 \AA)$ and high $(3.560 \AA)$ temperature lattice parameters with deformation difference defined as their difference.

\begin{tabular}{cccc}
\hline Cycle & $T D D_{L T} /$ no-units & $T D D_{H T} /$ no-units & $\Delta T D D /$ no-units \\
\hline 1 & $0.000 \%$ & $0.000 \%$ & $0.0000 \%$ \\
2 & $0.028 \%$ & $0.028 \%$ & $0.0003 \%$ \\
4 & $0.057 \%$ & $0.056 \%$ & $0.0006 \%$ \\
5 & $0.113 \%$ & $0.084 \%$ & $0.0291 \%$ \\
\hline
\end{tabular}

The TDD observed here, suggests that the $N i$ is either provided an insufficient time to relax residual stresses, is experiencing mechanical degradation due to accelerated thermal shock, or a combination of the two processes.

Firstly, unlike high-temperature thermal cycling $\left(\mathrm{ca} .1000^{\circ} \mathrm{C}\right)$, lower temperature cycling $\left(\mathrm{ca} .600^{\circ} \mathrm{C}\right)$ may require several thermal cycles or extended dwell times at operational temperatures before residual stresses can be relieved. Given the infrequency of thermal cycles in stationary CHP applications, extended dwell times at lower temperatures may allow sufficient time for residual stress relaxation, although, higher frequency operational cycling may require many cycles before residual stresses are relieved from the materials. Secondly, it is conceivable that the high thermal ramp-rates induce tensile stress within the $N i$ phase due to the difference 
in the $N i$ and YSZ thermal expansion coefficients, likely observed more notably in cooling due to the higher stress-state. Finally, a combination of relaxation and thermally induced shock would support the divergent paths of the high and low temperature deformations.

\section{Conclusion}

The influence of ceramic addition on thermo-mechanical performance was examined for two cermet materials with comparison to a ceramic-free metal sample.

Crystallographic information suggests that the effects of ceramic addition to the expansion of the FCC structure of $\mathrm{Ni}$ in isothermal environments are minor over a single thermal cycle. Nevertheless, over the lifetime of an SOFC the anode is expected to withstand multiple thermal cycles. Therefore, techniques such as accelerated stress testing should be employed to understand the accumulative effects of operational cycling.

$A S T$ revealed that lower temperature operation, i.e. $600{ }^{\circ} \mathrm{C}$ rather than higher $1000{ }^{\circ} \mathrm{C}$, results in deformation of the lattice parameters at both, low and high temperatures, likely due to a combination of two mechanisms: shock-induced tensile stress and delayed relaxation hysteresis. Furthermore, the high and low temperature deformation has been found to be divergent resulting in a greater relative deformation in the cold lattice parameters than that observed at high temperature.

A likely contributor to the thermally driven degradation on operational start-up and shut-down is the non-linear TEC peak found at the Curie temperature. Until now, macroscopic studies have understood that the ceramic backbones suppress the non-linear expansion of the $N i$ phase resulting in a subdual of the peak. However, this work demonstrates that the non-linearity remains within the crystallographic structure although shifted to a higher temperature, a temperature that is dependent upon the ceramic employed.

The crystallographic information presented here will aid in the thermo-mechanical understanding of ceramic-metal interaction within cermet materials, advancements which are not limited to use in electrochemical devices but also are applicable to broader cermet material applications.

$\begin{array}{ll}\text { Abbreviations } & \\ A S T & \text { Accelerated stress test } \\ C H P & \text { Combined heat and power } \\ F C C & \text { Face centered cubic } \\ G D C & \text { Gadolinium-doped ceria } \\ h, k \text { and } l & \text { Miller indices } \\ <h k l> & \text { Set of crystallographic directions } \\ N i & \text { Nickel } \\ N i O & \text { Nickel Oxide } \\ S O F C & \text { Solid oxide fuel cell } \\ T D D & \text { Thermally driven deformation } \\ T D D_{H T} & \text { Thermally driven deformation at high temperature } \\ T D D_{L T} & \text { Thermally driven deformation at low temperature } \\ T E C & \text { Thermal expansion coefficient } \\ U A V & \text { Unmanned aerial vehicle } \\ Y S Z & \text { Yttria-stabilized zirconia }\end{array}$

\section{Acknowledgements}

The authors would like to acknowledge the EPSRC (EP/M014045/1), the Centre for Doctoral training and the Royal Academy for Engineering for financial support. The authors would also like to thank the Paul Scherrer Institute (PSI) for the beam time allocation at the X04SA-MS beamline and Michael Lange for his expertise at the beamline.

\section{References}

1. Atkinson, A., Barnett, S., Gorte, R.J., Irvine, J.T.S., McEvoy, A.J., Mogensen, M., Singhal, S.C. and Vohs, J., 2004. Advanced anodes for high-temperature fuel cells. Nature materials, 3(1), pp.17-27.

2. Hawkes, A.D. and Leach, M.A., 2007. Cost-effective operating strategy for residential micro-combined heat and power. Energy, 32(5), pp.711-723.

3. Braun, R.J., Klein, S.A. and Reindl, D.T., 2006. Evaluation of system configurations for solid oxide fuel cell-based micro-combined heat and power generators in residential applications. Journal of Power Sources, 158(2), pp.12901305.

4. Barzi, Y.M., Ghassemi, M. and Hamedi, M.H., 2009. Numerical analysis of start-up operation of a tubular solid oxide fuel cell. international journal of hydrogen energy, 34(4), pp.2015-2025.

5. Achenbach, E., 1994. Three-dimensional and time-dependent simulation of a planar solid oxide fuel cell stack. Journal of power sources, 49(1), pp.333-348. 
6. Clague, R., Shearing, P.R., Lee, P.D., Zhang, Z., Brett, D.J.L., Marquis, A.J. and Brandon, N.P., 2011. Stress analysis of solid oxide fuel cell anode microstructure reconstructed from focused ion beam tomography. Journal of Power Sources, 196(21), pp. 9018-9021.

7. Robinson, J.B., Brown, L.D., Jervis, R., Taiwo, O.O., Millichamp, J., Mason, T.J., Neville, T.P., Eastwood, D.S., Reinhard, C., Lee, P.D. and Brett, D.J., 2014. A novel high-temperature furnace for combined in situ synchrotron Xray diffraction and infrared thermal imaging to investigate the effects of thermal gradients upon the structure of ceramic materials. Journal of synchrotron radiation, 21(5), pp.1134-1139.

8. Pomfret, M.B., Steinhurst, D.A., Kidwell, D.A. and Owrutsky, J.C., 2010. Thermal imaging of solid oxide fuel cell anode processes. Journal of Power Sources, 195(1), pp.257-262.

9. Brett, D.J.L., Aguiar, P., Clague, R., Marquis, A.J., Schöttl, S., Simpson, R. and Brandon, N.P., 2007. Application of infrared thermal imaging to the study of pellet solid oxide fuel cells. Journal of power sources, 166(1), pp.112-119.

10. Yakal-Kremski, K., Cronin, J.S., Chen-Wiegart, Y.C., Wang, J. and Barnett, S.A., 2013. Studies of solid oxide fuel cell electrode evolution using 3D tomography. Fuel Cells, 13(4), pp.449-454.

11. Shearing, P.R., Bradley, R.S., Gelb, J., Tariq, F., Withers, P.J. and Brandon, N.P., 2012. Exploring microstructural changes associated with oxidation in Ni-YSZ SOFC electrodes using high resolution X-ray computed tomography. Solid State Ionics, 216, pp.69-72.

12. Robinson, J.B., Engebretsen, E., Brown, L.D., Clague, R., Eastwood, D., Reinhard, C., Lee, P., Brett, D.J. and Shearing, P.R., 2015. Thermal Gradients in Solid Oxide Fuel Cell Anodes: X-Ray Diffraction, Thermal Imaging and Model Prediction. ECS Transactions, 68(1), pp.1053-1067.

13. Nielsen, J. and Hjelm, J., 2014. Impedance of SOFC electrodes: A review and a comprehensive case study on the impedance of LSM: YSZ cathodes. Electrochimica Acta, 115, pp.31-45.

14. Kennouche, D., Hong, J., Noh, H.S., Son, J.W. and Barnett, S.A., 2014. Three-dimensional microstructure of highperformance pulsed-laser deposited Ni-YSZ SOFC anodes. Physical Chemistry Chemical Physics, 16(29), pp.1524915255 .

15. Wilson, J.R., Kobsiriphat, W., Mendoza, R., Chen, H.Y., Hiller, J.M., Miller, D.J., Thornton, K., Voorhees, P.W., Adler, S.B. and Barnett, S.A., 2006. Three-dimensional reconstruction of a solid-oxide fuel-cell anode. Nature materials, 5(7), pp.541-544.

16. Heenan, T. M. M., Bailey, J. J., Lu, X., Robinson, J. B., Iacoviello, F., Finegan, D. P., Brett, D. J. L. and Shearing, P. R., 2016. Three-Phase Segmentation of Solid Oxide Fuel Cell Anode Materials Using Lab Based X-ray NanoComputed Tomography. Fuel Cells.

17. Steele, B.C.H., 1994. Oxygen transport and exchange in oxide ceramics. Journal of power sources, 49(1-3), pp. 1-14.

18. Kharton, V.V., Marques, F.M.B. and Atkinson, A., 2004. Transport properties of solid oxide electrolyte ceramics: a brief review. Solid State Ionics, 174(1), pp. 135-149.

19. Rosenbohm, V.E., 1938. Über eine einrichtung zur photographischen aufzeichnung der linearenwärmeausdehnungvonmetallen. Ausdehnungskoeffizient von kupfer und nickel. Physica, 5, pp. 385 - 398.

20. White G. K, 1965. Proc. Phys. Soc. London 86, 159.

21. Clark, A.F., 1968. Low temperature thermal expansion of some metallic alloys. Cryogenics, 8(5), pp. 282 - 289.

22. Suh, I.K., Ohta, H. and Waseda, Y., 1988. High-temperature thermal expansion of six metallic elements measured by dilatation method and X-ray diffraction. Journal of Materials Science, 23(2), pp. $757-760$.

23. R. K. Kirby, in American Institute of Physics Handbook, 2nd ed. (McGraw-Hill, New York, 1963), pp. 4 - 64.

24. Robinson, J.B., Brown, L.D., Jervis, R., Taiwo, O.O., Heenan, T.M., Millichamp, J., Mason, T.J., Neville, T.P., Clague, R., Eastwood, D.S. and Reinhard, C., 2015. Investigating the effect of thermal gradients on stress in solid oxide fuel cell anodes using combined synchrotron radiation and thermal imaging. Journal of Power Sources, 288, pp.473-481.

25. Blum, L., 2017. An Analysis of Contact Problems in Solid Oxide Fuel Cell Stacks Arising from Differences in Thermal Expansion Coefficients. Electrochimica Acta, 223, pp.100-108.

26. Sumi, H., Ukai, K., Yokoyama, M., MizutaNi, Y., Doi, Y., Machiya, S., Akiniwa, Y. and Tanaka, K., 2006. Changes of internal stress in solid-oxide fuel cell during red-ox cycle evaluated by in situ measurement with synchrotron radiation. Journal of fuel cell science and technology, 3(1), pp.68-74.

27. ResiNi, C., Delgado, M.C.H., Presto, S., Alemany, L.J., RiaNi, P., Marazza, R., Ramis, G. and Busca, G., 2008. Yttriastabilized zirconia (YSZ) supported Ni-Co alloys (precursor of SOFC anodes) as catalysts for the steam reforming of ethanol. International Journal of Hydrogen Energy, 33(14), pp.3728-3735.

28. Lin, C.K., Chen, T.T., Chyou, Y.P. and Chiang, L.K., 2007. Thermal stress analysis of a planar SOFC stack. Journal of Power Sources, 164(1), pp.238-251.

29. Chiang, L.K., Liu, H.C., Shiu, Y.H., Lee, C.H. and Lee, R.Y., 2008. Thermo-electrochemical and thermal stress analysis for an anode-supported SOFC cell. Renewable Energy, 33(12), pp.2580-2588.

30. Cepeda-Jiménez, C.M., Hernando, A., Barandiarán, J.M. and Pérez-Prado, M.T., 2016. Onset of room temperature ferromagnetism by plastic deformation in three paramagnetic pure metals. Scripta Materialia, 118, pp. 41-45.

31. Šepelák, V., Baabe, D., Mienert, D., Schultze, D., Krumeich, F., Litterst, F.J. and Becker, K.D., 2003. Evolution of structure and magnetic properties with annealing temperature in nanoscale high-energy-milled nickel ferrite. Journal of Magnetism and Magnetic Materials, 257(2), pp.377-386.

32. Mori, M., Yamamoto, T., Itoh, H., Inaba, H. and Tagawa, H., 1998. Thermal Expansion of Nickel-Zirconia Anodes in Solid Oxide Fuel Cells during Fabrication and Operation. Journal of the Electrochemical Society, 145(4), pp. $1374-$ 1381.

33. Radovic, M., Lara-Curzio, E., Trejo, R.M., Wang, H. and Porter, W.D., 2009. Thermophysical Properties of YSZ and $\mathrm{Ni}-\mathrm{YSZ}$ as a Function of Temperature and Porosity. Advances in Solid Oxide Fuel Cells II: Ceramic Engineering and Science Proceedings, Cocoa Beach, Volume 27, (4), p.79. 
34. Matsui, T., Kim, J.Y., Muroyama, H., Shimazu, M., Abe, T., Miyao, M. and Eguchi, K., 2012. Anode microstructural change upon long-term operation for the cathode-supported tubular-type SOFC. Solid State Ionics, 225, pp.50-54.

35. Willmott, P.R., Meister, D., Leake, S.J., Lange, M., Bergamaschi, A., Böge, M., Calvi, M., Cancellieri, C., Casati, N., Cervellino, A. and Chen, Q., 2013. The materials science beamline upgrade at the Swiss Light Source. Journal of synchrotron radiation, 20(5), pp.667-682.

36. Huber, http://www.xhuber.de/, 2017.

37. Ning, X., Selesnick, I.W. and Duval, L., 2014. Chromatogram baseline estimation and denoising using sparsity (BEADS). Chemometrics and Intelligent Laboratory Systems, 139, pp.156-167.

38. Pihlatie, M., Kaiser, A. and Mogensen, M., 2009. Mechanical properties of NiO/Ni-YSZ composites depending on temperature, porosity and redox cycling. Journal of the European Ceramic Society, 29(9), pp.1657-1664.

39. Luo, Yun, et al. "Effects of anode porosity on thermal stress and failure probability of planar solid oxide fuel cell with bonded compliant seal." International Journal of Hydrogen Energy 41.18 (2016): 7464-7474.

40. Tariq, F., Kishimoto, M., Yufit, V., Cui, G., Somalu, M. and Brandon, N.P., 2014. 3D imaging and quantification of interfaces in SOFC anodes. Journal of the European Ceramic Society, 34(15), pp.3755-3761.

41. Celik, S., Ibrahimoglu, B., Toros, S. and Mat, M.D., 2014. Three dimensional stress analysis of solid oxide fuel cell anode micro structure. International Journal of Hydrogen Energy, 39(33), pp.19119-19131. 